\title{
A study on glycemic control and related complications in type I diabetic children
}

\author{
Alkarani T Patil ${ }^{1}$, Rajashekara Murthy G R $^{2}$, Hema GR $^{3}$ \\ ${ }^{1}$ Dr Alkarani T Patil, Associate Professor of Pediatrics, ${ }^{2}$ Dr Rajashekara Murthy G R, Associate Professor of Pediatrics, \\ ${ }^{3}$ Dr Hema G R, Post Graduate. All are affiliated with Department of Pediatrics, Indira Gandhi Institute of Child Health, \\ Banglore, Karnataka, India
}

Address for Correspondence: Dr Alkarani T Patil, No.885, $22^{\text {nd }}$ Cross, $7^{\text {th }}$ Sector, H.S.R. Layout, Bangalore, Email : alkaranipatilurs@gmail.com

\begin{abstract}
Introduction: Type I Diabetes Mellitus is a common, chronic, metabolic syndrome characterized by hyperglycaemia as a cardinal biochemical feature. Patients with diabetes mellitus face an increased risk of morbidity and mortality due to micro and macrovascular complications caused by diabetes. There is lack of Indian studies on diabetic children. Hence this study was undertaken to know glycaemic control and related complications in type I diabetes mellitus. Materials and methods: This is a Prospective study conducted in Diabetic Clinic at Indira Gandhi institute of Child Health, Bengaluru for 1 year. Study group had 34 diabetic children; they were followed up for period of one year to assess glycaemic control and complications of the disease. Results: 34 children were followed up for a period of one year to study glycaemic control and related complications. Glycaemic control was assessed using HbAlc. Seven children had good and 27 had poor glycaemic control. Factors associated with poor glycemic control were analyzed. Age at onset of the disease more than 12, duration of disease more than 5 years, female children in pre-pubertal age were associated with poor control. Children were followed up for development of complications. 4 children presented with DKA (11.76\%), 12 had hypoglycaemia (35.29\%). Conclusion: Poor glycaemic control was associated with longer duration of disease, female sex and disease being diagnosed in pubertal period.
\end{abstract}

Keywords: Type 1 Diabetes, Glycaemic Control, HbA1c, Complications.

\section{Introduction}

Diabetes Mellitus is a chronic metabolic syndrome which is characterized by hyperglycemia as a predominant biochemical feature [1]. Diabetes is divided into two major forms: (i) those caused by deficiency in the secretion of insulin caused by damage to the $\beta$-cell of pancreas (type $1 \mathrm{DM}$ ), and (ii) those that are a result of insulin resistance occurring at the level of adipose tissue, skeletal muscle and liver, with various degrees of $\beta$-cell dysfunction (type 2 DM) [1].

Below the age of 15 years, the incidence of type 1 diabetes is increasing among children in many countries. About 78,000 children $<15$ years of age are estimated to develop type $1 \mathrm{DM}$ annually worldwide, with overall annual increase estimated to be $3 \%$ [2]. Of the $4,90,000$ children with type $1 \mathrm{DM}, 24 \%$ of children

Manuscript received: $24^{\text {th }}$ Oct 2015

Reviewed: $5^{\text {th }}$ Nov 2015

Author Corrected: $17^{\text {th }}$ Nov 2015

Accepted for Publication: $8^{\text {th }}$ Dec 2015 are from the European region, and 23\% from the SouthEast Asia [2]. The prevalence of children with type 1 DM in South-East Asia, according to International Diabetic federation is estimated to be high. An estimated 18,000 children $<15$ years of age in the regions (Nainital, Uttarakhand, Ratlam, Madhya Pradesh, and Bhilwara in Rajasthan) were newly diagnosed for type 1 DM in the year 2011 [2].

Strict glycemic control is absolutely necessary in the treatment of diabetic children to prevent micro and macro vascular complications in the future as demonstrated in the Diabetes Control and Complications Trial research (DCCT) study [1]. Hyperglycemia is a necessary factor but not adequate enough for development of diabetic nephropathy [3], whereas hyperglycemia seems to be the significant risk factor for proliferative retinopathy [4]. During Puberty, rapid growth and hormonal changes occur in the body 
and is often characterized by impairment in glycemic control, and all these factors may advance the development of complications in diabetes $[5,6]$. It has been addressed that early, pre-pubertal strict glycaemic control contributes to the advancement of microvascular complications to a lesser grade [7]. But, microvascular complications can even occur early in the prepubertal years [8-10] and there is need for both short and longterm glycaemic control [11]. There is a lack of Indian data to support these findings. Hence this study was done to study the glycaemic control and related complications in Type 1 Diabetic children.

\section{Materials \& Methods}

This is a prospective study for one year between February 2011 to January 2012 at Indira Gandhi institute of child health, Bangalore, with the objective to study the glycemic control and related complications in type I diabetic children.

Children aged between 1-18 years, diagnosed as diabetes as per American Diabetes Association (ADA) criteria for diabetes mellitus [symptoms suggestive of diabetes plus random plasma glucose $\geq 200 \mathrm{mg} / \mathrm{dl}$ (11.1 $\mathrm{mmol} / \mathrm{L})$ or fasting plasma glucose $\geq 126 \mathrm{mg} / \mathrm{dl} \quad(7.0$ $\mathrm{mmol} / \mathrm{L})$ or presenting with complications) were included [12].

Children $<1$ year and $>18$ years and those with transient or stress induced hyperglycaemia were excluded from the study. Data collection was done using a structured proforma which included disease related characteristics and demographic factors.

Clinical examination was done in all children including Tanners staging. In addition to routine investigations, HbA1c estimation of all cases was done with highperformance liquid chromatography (HPLC) and the children were assessed for glycaemic control as per ADA Criteria by classifying them into preschoolers, school age and adolescents with $\mathrm{HbA1c}$ of $\leq 8.5 \%$, $\leq$ $7.5 \%$ and $\leq 7 \%$ respectively [13]. Children were followed up for one year to assess the short term and long term complications of diabetes as per screening guidelines of ADA.
Children presenting with DKA were classified as mild, moderate and severe as per ISPAD guidelines [14] and were assessed for the development of complications. Children diagnosed as diabetes presenting with hypoglycaemia were classified as asymptomatic and symptomatic as per ADA recommendation. Microalbuminuria was assessed using spot albumincreatinine excretion and was classified as per American Diabetic Association recommendation [13]: microalbuminuria: 30-299 microgram/mg creatinine and macro (clinical) albuminuria $\geq 300 \mathrm{microgram} / \mathrm{mg}$ creatinine. Diabetic Retinopathy was assessed by fundus examination.

Neuropathy was assessed clinically for the loss of pain, temperature, vibration perception and position sense, or presence of abnormal sensations in the limbs suggesting peripheral neuropathy and 10 -g monofilament pressure sensation at the distal plantar aspect of both great toes and metatarsal joints, and assessment of ankle reflexes. Limited Joint Mobility (LJM) was assessed clinically for the presence of prayer sign, which is due to metabolic perturbations in diabetes (including glycosylation of collagen consequent to prolonged hyperglycemia, which results in abnormal cross linkage of collagen which renders it resistant to mechanical and enzymatic degradation and collagen accumulation in skin and periarticular structures; microvascular abnormalities with damage to blood vessels and nerves) resulting in changes in the connective tissue $[15,16]$.

Insulin requirement in units per $\mathrm{kg}$ at the beginning and end of the study and regularity of the clinical visits was assessed. Adherence to diet was assessed as per ISPAD recommendations. Children were assessed for comorbidities like hypothyroidism with relevant clinical and laboratory investigations. Children were classified as good glycemic control and poor glycemic control group according to the target level of $\mathrm{HbAlc}$ for age, recommended by the ADA [13]. The findings of the study were analyzed to find out the Glycemic Control and complications of the disease. Data thus obtained was analyzed in SPSS software and Fisher Exact test was used to see how different factors influenced different outcomes.

\section{Results}

The study group had 34 children with type I Diabetes Mellitus. Adolescents were the majority with 47\%. Twenty(58.8\%) were females and 14(41.2\%) were males. F: M=1.4:1. Eighteen(52.9\%) were from rural area and 16(47.1\%) from urban area. Eighteen (52.95) had a duration of disease less than 5 years and 16(47.1\%) had a duration of more than 5 years. None had delayed puberty. 
$61.77 \%$ of the total were underweight, $35.30 \%$ had a normal BMI. 7(20.6\%) had good glycaemic control and $27(79.4 \%)$ had poor glycaemic control. 12 children had hypoglycaemia. $8(23.5 \%)$ had symptomatic hypoglycaemia and $4(11.8 \%)$ had asymptomatic hypoglycaemia.

Table No. 1: Demographic data, duration of treatment, BMI and hypoglycemia

\begin{tabular}{|c|c|c|}
\hline Data & Number & Percentage \\
\hline $\begin{array}{l}\text { Age distribution } \\
1-6 \text { Yrs } \\
7-12 \text { Yrs } \\
13-17 \text { Yrs }\end{array}$ & $\begin{array}{c}5 \\
13 \\
16\end{array}$ & $\begin{array}{l}14.70 \\
38.23 \\
47.05\end{array}$ \\
\hline $\begin{array}{l}\text { Sex } \\
\text { Female } \\
\text { Male }\end{array}$ & $\begin{array}{l}20 \\
14\end{array}$ & $\begin{array}{l}58.8 \\
41.2\end{array}$ \\
\hline $\begin{array}{l}\text { Region } \\
\text { Rural } \\
\text { Urban }\end{array}$ & $\begin{array}{l}18 \\
16\end{array}$ & $\begin{array}{l}52.9 \\
47.1\end{array}$ \\
\hline $\begin{array}{l}\text { Duration of Treatment in years } \\
1-5 \text { years } \\
>5 \text { years }\end{array}$ & $\begin{array}{c}18 \\
16\end{array}$ & $\begin{array}{l}52.9 \\
47.1\end{array}$ \\
\hline $\begin{array}{l}\text { BMI } \\
\text { Underweight } \\
\text { Normal } \\
\text { Overweight }\end{array}$ & $\begin{array}{c}21 \\
12 \\
1\end{array}$ & $\begin{array}{c}61.77 \\
35.29 \\
2.9\end{array}$ \\
\hline $\begin{array}{l}\text { Hypoglycemia } \\
\text { Absent } \\
\text { Asymptomatic } \\
\text { Symptomatic }\end{array}$ & $\begin{array}{c}22 \\
4 \\
8\end{array}$ & $\begin{array}{l}64.7 \\
11.8 \\
23.5\end{array}$ \\
\hline
\end{tabular}

Table No 2: Complications of Diabetes Mellitus

\begin{tabular}{|c|c|c|}
\hline Complications & Number & Percentage \\
\hline DKA & 4 & 35.29 \\
\hline Hypoglycaemia & 12 & 2.9 \\
\hline Nephropathy & 1 & 0 \\
\hline Retinopathy & 1 & 2.9 \\
\hline Neuropathy & 3 & 8.82 \\
\hline Limitation of joint mobility & 8 & 23.52 \\
\hline Lipohypertrophy & 0 & 2 \\
\hline
\end{tabular}

Out of 34 children, short term complications like DKA and hypoglycaemia were noticed in 4[11.76\%] and 12[35.29\%]. Microvascular complications like nephropathy and neuropathy were noted in $1[2.9 \%]$ child for each group. Limitation of joint mobility was noted in three children $(8.82 \%)$. 
Adolescents had poor glycemic control $(\mathrm{p}=0.008)$. Insulin requirement in units per $\mathrm{kg}$ was 0.77 in children with good glycaemic control and 0.87 in poor glycaemic control. Hypoglycemia was more in children with good glycaemic control $(\mathrm{p}=0.034)$.

Table No 3: Association of various factors with glycemic control

\begin{tabular}{|l|c|c|c|}
\hline Factor & Good control (n \& \%) & Poor control (n \& \%) & $\begin{array}{c}\text { Fisher exact test } \\
\text { p-value }\end{array}$ \\
\hline Age at diagnosis & $7(38.7)$ & $11(64.37)$ & 0.008 \\
$1-12$ yrs & 0 & $16(100)$ & \\
$>12$ yrs & $3(15)$ & $17(85)$ & 0.4099 \\
\hline Sex & $4(28.6)$ & $10(78.4)$ & 0.681 \\
Female & $3(16.7)$ & $15(83.3)$ & \\
Male & $4(25)$ & $12(75)$ & 0.441 \\
\hline Duration of Diabetes & & & \\
$\leq 5$ years & $6(23.33)$ & $23(76.67)$ & \\
$>5$ years & $0(0)$ & $4(100)$ & 0.034 \\
\hline DKA & $2(28.57)$ & $20(74.1)$ & \\
Absent & $5(71.43)$ & $7(25.93)$ & \\
Present & & & \\
\hline Hypoglycemia & & & \\
Absent & & & \\
Present & & & \\
\hline
\end{tabular}

\section{Discussion}

The primary objective of the study was to analyze the glycemic control and related complications in Type 1 diabetic children. This study included 34 children with type 1 diabetes mellitus who were followed up for a period of one year. For glycaemic control, age was found to be an important factor.

Children with poor glycaemic control had higher mean age of 13.5 years than those with good glycemic control. Vanelli M al [17] who studied children and adolescents with diabetes, found that increasing age was associated with a higher mean $\mathrm{HbA} 1 \mathrm{c}$. Adolescents tend to have worst glycaemic control than younger children with DM [17].

Dramatic changes occur during puberty, which includes the acceleration and cessation of somatic growth, the development of secondary sexual characteristics, and onset of reproductive function [17].

Furthermore, exposure to stressful conditions associated with puberty may aid to the poor glycaemic control through stimulation of the autonomic nervous system to induce hyperglycaemia [17]. The poor glycaemic control in adolescents relates to the rapid biologic changes of puberty along with challenges of adapting to life style that require self-management of dietary practices, exercise behaviors, and insulin adjustment [18].
It was noticed in this study that gender was not associated with glycaemic control. But when we compared patients of different age groups according to gender, we found that female patients aged $>12$ years had higher percent $(68.75 \%)$ of poor glycaemic control than males of the same age group (31.25\%). This result has been recorded by Setoodeh et al [19] who attributed to the high fat content of their bodies with subsequent increase in adipocytokines as peptin and adiponectin which decreases insulin sensitivity [19].

In our study, patients with BMI below normal had higher proportion of good control than patients who had a normal BMI or were overweight. This was similar with the results of Mohammed et al. [18]. In the present study, $22.22 \%$ of the children in the group with duration of disease $<5$ years had a good glycaemic control and $83.34 \%$ had poor control with duration of disease $>$ 5years which was similar to the results in the study done by Mohammed et al. The worsening glycaemic control with increasing duration in type $1 \mathrm{DM}$ is due to progressive loss of beta cell function and the difficulty of the patients to continuously monitor blood glucose level and adjust to the regimen of treatment, diet, and exercise [18].

Children who were young $(<12$ years $)$ at onset of disease were having good glycaemic control, whereas 
patients who are old ( $>12$ years) at onset of disease were in the group of poor glycaemic control $(\mathrm{p}<0.0008)$. E.M Gerstl et al demonstrated a strong association between glycaemic control and patient age. Children aged $<10$ years had a mean HbA1c of 7.6, children aged 11-20 years had a significantly higher average level of glycaemic control $(\mathrm{p}<0.0001)$ [20]. The results of Hvidore study also showed an increase in HbA1c from $8.3 \%$ in children < 11years of age to $8.9 \%$ in children aged $12-18$ years [21].

Insulin required in units per $\mathrm{kg}$ was comparable in both the groups. Adherence to diet was comparable in both the groups. Of the 34 children studied, 19 children had complications of diabetes mellitus. DKA was found in $4(11.76 \%)$ children, one child presenting as severe DKA and remaining three as moderate DKA, hypoglycaemia in 12 (35.29\%) children, of which 8 had symptomatic hypoglycaemia requiring some form of assistance as either oral or intravenous glucose and 4 had asymptomatic hypoglycaemia. One child had urine microalbuminuria positive (323microgram $/ \mathrm{mg}$ of creatinine) who was diagnosed to have diabetes at the age of 1 year, with a duration of disease of 9.5 years. She was started on tablet enalapril, following which the albuminuria decreased (115microgram $/ \mathrm{mg}$ of creatinine). One child who is presently 16 years developed neuropathy with a duration of diabetes of 10.5 years. 3 children developed limited joint mobility and 8 had lipohypertrophy. None developed retinopathy during our study period. Revers et al has studied the relation between DKA and lower socio-economic status and have found that DKA is increased in patients with lower socio-economic status [22].

Maria E. Craig et al have reported that severe hypoglycaemia was more frequent in those with HbA1c level lower than $8 \%$ and was lowest in those with an HbA1c level higher than $9 \%$. In our study also we found a similar relation between $\mathrm{HbA} 1 \mathrm{c}$ and glycaemic control. Children with good control had more episodes of hypoglycaemia than with poor glycaemic control ( $p$ $0.034)$ [23].

$\mathrm{K}$ Izumi et al have reported an increase in the incidence of retinopathy with poor glycaemic control.25\% in those with $\mathrm{HbA} 1 \mathrm{c} \geq 12.5,7.3 \%$ with $\mathrm{HbA} 1 \mathrm{c}$ of $10-12.4$ and none with lower HbA1c level [24].

Donaghue et al [25] and Mohsin et al [26] have found that microalbuminuria is consistent with adolescents and increases with duration of diabetes in years.
Silverstein et al have demonstrated a clinically substantial 2-fold to 3-fold risk of LJM with $\mathrm{HbA1C}$ levels above $8 \%$ on average over a period of years. For every $1 \%$ increase in $\mathrm{HbA} 1 \mathrm{C}$ level, there was a 2.5 -fold increase in the risk of LJM and the routine monitoring of joint mobility in clinical practice, performed by passive manipulation, can provide an indicator of longterm status and risk of complications, however, checking for LJM cannot substitute for appropriate ophthalmologic and renal evaluation for early detection of complications because a substantial proportion of patients will experience these complications without limited joint mobility [27].

\section{Conclusion}

Female adolescents, older age at disease presentation and children with duration of diabetes more than 5 years are prone to have poor glycemic control. Hypoglycemia is the common complication, followed by Diabetic Ketoacidosis and Limitation of joint mobility. Hypoglycemia is associated with children who had good glycemic control and younger age group. Routine monitoring of joint mobility, educating the parents/caregivers about the prevention of diabetic ketoacidosis and hypoglycemia is recommended in preventing these complications.

Ethical approval: Obtained from Institutional Ethics Committee (Human Studies)

Funding: No funding sources.

Conflict of Interest: The authors declare no conflict of interest.

\section{References}

1. Alemzadeh R, Ali O. Diabetes Mellitus in children, Kliegman et al, Nelson textbook of paediatrics, 19 $9^{\text {th }}$ edition. Philadelphia: Elsevier Saunders; 2011. p.1968-1997.

2. Diabetes in the young in International Diabetes Federation. IDF Diabetes Atlas. 5th edition. International Diabetic Federation: Brussels, Belgium, 2011. p.34. https://www.idf.org/sites/default/files/21991_diabAtlas _5thEd.pdf

3. Svensson M, Eriksson JW, Dahlquist G. Early glycemic control, age at onset, and development of microvascular complications in childhood-onset type 1 diabetes: a population-based study in northern Sweden. Diabetes Care. 2004 Apr;27(4):955-62. 
4. Keen H, Lee ET, Russell D, Miki E, Bennett PH, Lu $\mathrm{M}$. The appearance of retinopathy and progression to proliferative retinopathy: the WHO Multinational Study of Vascular Disease in Diabetes. Diabetologia. 2001 Sep;44(Suppl 2):S22-30.

5. The DIAMOND Project Group. Incidence and trends of childhood Type 1 diabetes worldwide 1990-1999. Diabet Med 2006;23(8):857-866.

6. Patterson CC, Dahlquist GG, Gyurus E, Green A, Soltész G; EURODIAB Study Group. Incidence trends for childhood type 1 diabetes in Europe during 1989-2003 and predicted new cases 2005-20: a multicentre prospective registration study. Lancet 2009 Jun;373(9680):2027-33. doi: 10.1016/S01406736(09)60568-7.

7. Green A, Brutti G, Patterson CC, et al. Variation and trends in incidence of childhood diabetes in Europe. EURODIAB ACE study group. Lancet 2000 Mar;355(9207):873-6.

8. Barrett JC, Clayton DG, Concannon P, Akolkar B, Cooper JD, Erlich HA et al. Genome-wide association study and meta-analysis find that over 40 loci affect risk of type 1 diabetes. Nat Genet. 2009 Jun;41(6):703-7. doi: 10.1038/ng.381. Epub 2009 May 10 .

9. Concannon P, Chen WM, Julier C, Morahan G, Akolkar B, Erlich HA et al. Genome-wide scan for linkage to type 1 diabetes in 2,496 multiplex families from the Type 1 Diabetes Genetics Consortium. Diabetes 2009 Apr;58(4):1018-1022.

10. Lambert AP, Gillespie KM, Thomson G, Cordell HJ, Todd JA, Gale EA et al. Absolute risk of childhoodonset type 1 diabetes defined by human leukocyte antigen class II genotype: a population-based study in the United Kingdom. J ClinEndocrinolMetab. 2004 Aug;89(8):4037-4043.

11. Skyler JS, Krischer JP, Wolfsdorf J, Cowie C, Palmer JP, Greenbaum C et al. Effects of oral insulin in relatives of patients with type 1 diabetes: The Diabetes Prevention Trial - Type 1. Diabetes Care 2005 May;28(5):1068-76.

12. American Diabetes Association. Diagnosis and Classification of Diabetes Mellitus. Diabetes Care. 2010 Jan;33(Suppl 1): S62-S69. doi: 10.2337/dc10-S062.
13. American Diabetes Association. Standards of Medical Care in Diabetes. Diabetes Care. 2011 Jan;34 (Suppl 1): S11-S61. doi: 10.2337/dc11-S011.

14. Wolfsdorf J, Craig ME, Daneman D, Dunger D, Edge J, Lee W, et al. ISPAD Clinical Practice Consensus Guidelines 2009 Compendium. Diabetic ketoacidosis in children and adolescents with diabetes. Pediatr Diabetes. 2009 Sep;10(Suppl. 12):118-133. doi: 10.1111/j.1399-5448.2009.00569.x.

15. Ballantyne JA, Hooper G. The hand and diabetes. Current Orthopaedics.2004;18:118-25.

16. Kim RP, Edelman SV, Kim. Musculoskeletal Complications of Diabetes Mellitus. Clinical Diabetes. 2001;19(3):132-5.

17. Vanelli M, Cerutti F, Chiarelli F, Lorini R, Meschi F; MCDC-Italy Group. Nationwide cross sectional survey of 3560 children and adolescents with diabetes in Italy. J Endocrinol Invest. 2005 Sep; 28(8):692-9.

18. Mohammed HA, Farghaly HS, Metwalley KA, Monazea EM, Abd El-Hafeez HA. Predictors of glycaemic control in children with type 1 diabetes mellitus in Assiut Egypt. Indian J of Endocrinol Metab. 2012 Sep;16(5):796-802. doi: 10.4103/22308210.100679 .

19. Setoodeh A, Mostafavi F, Rabbani A, Hedayat T. Female sex as a risk factor for glycaemic control and complications in Iranian patients with type one diabetes mellitus. Iran J Pediatr 2011 Sep;21(3):373-8.

20. Gerstl EM, Rabl W, Rosenbauer J, Gröbe H, Hofer SE, Krause U et al. Metabolic control as reflected by HbA1c in children, adolescents and young adults with type-1 diabetes mellitus: combined longitudinal analysis including 27,035 patients from 207 centers in Germany and Austria during the last decade. Eur J Pediatr. 2008 Apr;167(4):447-53. Epub 2007 Oct 9.

21. Mortensen HB, Hougaard P. Comparison of metabolic control in a cross sectional study of 2,873 children and adolescents with IDDM from 18 countries. The Hvidore study group on childhood diabetes. Diabetes Care. 1997 May;20(5):714-20.

22. Revers et al. Diabetic Ketoacidosis, Diabetic care, 29;2006:1190-1220 
23. Craig ME, Jones TW, Silink M, Ping YJ. Diabetes care, glycemic control, and complications in children with type 1 diabetes from Asia and the Western Pacific Region. J Diabetes Complications. 2007 SepOct;21(5):280-7.

24. Izumi K; Hoshi M; Kuno S; Okuno G; Yamazaki Y; Isshiki $G$ et al. Glycemic control, growth and complications in children with insulin-dependent diabetes mellitus - a study of children enrolled in a summer camp program for diabetics in Kinki district, Japan. Diabetes research and clinical practice. 1995 Jun;28(3):185-90
25. Donaghue, KC, Fairchild JM, Craig ME, Chan AK, Hing S, Cutler LR et al. Do all prepubertal years of diabetes duration contribute equally to diabetes complications? Diabetes Care. 2003 Apr; 26(4),1224-9.

26. Mohsin F, Craig ME, Cusumano J, Chan AK, Hing $\mathrm{S}$, Lee JW et al. Discordant trends in microvascular complications in adolescents with type 1 diabetes from 1990 to 2002. Diabetes Care. 2005 Aug;28(8):1974-80.

27. Silverstein JH, Gordon G, Pollock BH, Rosenbloom AL: Long-term glycemic control influences the onset of limited joint mobility in type 1 diabetes. J Pediatr. 1998 Jun;132(6):944-7.

\section{How to cite this article?}

Alkarani T Patil, Rajashekara Murthy GR, Hema GR. A study on glycemic control and related complications in type I diabetic children. Pediatr Rev: Int J Pediatr Res 2015;2(4):100-106.doi:10.17511/ijpr.2015.i04.12 